\title{
dSPACE DS1104 Based Real Time Implementation of Sliding Mode Control of Induction Motor
}

\author{
A. Omari ${ }^{1}$, I. K. Bousserhane ${ }^{2}$, A. Hazzab ${ }^{3}$, B. Bouchiba ${ }^{4}$ \\ ${ }^{1,3,4}$ Analyse et Optimisation des Systèmes Electro-Energétiques CAOSEE, University Tahri Mohamed of Bechar, Algeria \\ ${ }^{2}$ Smart Grids \& Renewable Energies Laboratory, University Tahri Mohamed of Bechar, Algeria
}

\begin{tabular}{|c|c|}
\hline Article Info & ABSTRACT \\
\hline Article history: & \multirow{7}{*}{$\begin{array}{l}\text { In this paper, the design of a speed control scheme based on a total sliding } \\
\text { mode control for Indirect Field Oriented of a three phase induction motor } \\
\text { (IM) is proposed. Firstly, the indirect field oriented control is derived. Then, } \\
\text { sliding mode control design is investigated to achieve a speed tracking } \\
\text { objective under different load torque disturbance. Finally a dSPACE DS1104 } \\
\text { R\&D board is used to implement the proposed scheme. The experimental } \\
\text { results released on } 0.25 \mathrm{~kW} \text { slip-ring IM show a high dynamic performance, } \\
\text { fast transient response without overshot as well as a good load disturbances } \\
\text { rejection response. }\end{array}$} \\
\hline Received Dec 15, 2017 & \\
\hline Revised Jan 18, 2018 & \\
\hline Accepted Feb 20, 2018 & \\
\hline & \\
\hline Keyword: & \\
\hline dSPACE DS1104 & \\
\hline
\end{tabular}

Field-oriented control

Induction motor

Sliding mode control

Copyright $@ 2018$ Institute of Advanced Engineering and Science. All rights reserved.

\section{Corresponding Author:}

Aymen Omari,

Departement of Electrical Engineering,

(CAOSEE) Laboratory, Tahri Mohamed Bechar University, Algeria

University Tahri Mohamed of Bechar, B.P 417 Bechar 08000, Algeria.

Email: aymen_elec@yahoo.fr

\section{INTRODUCTION}

Recently, significant advances in power electronics have brought considerable developments in the control of AC machines and high performance real-time implementation [1], [11], 22]. The field-oriented control technique has been widely used in industry for high-performance IM drive [2], [3], [22], [24], where the knowledge of synchronous angular velocity is often necessary in the phase transformation for achieving the favourable decoupling control between motor torque and rotor flux as for a separately excited DC machine. This control strategy can provide the same performance as achieved from a separately excited DC machine [2], [22], [23], [25]. This technique can be performed by two basic methods: direct vector control and indirect vector control. Both DFO and IFO solutions have been implemented in industrial drives demonstrating performances suitable for a wide spectrum of technological applications. This stimulated a significant research activity to develop IM vector control algorithms using nonlinear control theory in order to improve performances, achieving speed (or torque) and flux tracking, or to give a theoretical justification of the existing solutions [2], [3], [8], [22].

Sliding mode control (SMC), due to its order reduction, disturbance rejection and strong robustness properties, along with its simple implementation by means of power converters, is one of the prospective control methodologies for electrical machines [10], [15], [16], 17]. Sliding mode control is a type of variable structure scheme, i.e. which involves switching between controllers which is relatively independent of parametric uncertainties and load disturbances. SMC has been employed for position and speed control of ac machines. However, the discontinuous nature of the switching feature of SMC causes chattering in the control system [13], [14], [15], 16].

In this paper, a total sliding mode controller based on indirect field orientation is proposed for IM speed control. The proposed controller is applied to achieve a speed control under disturbances of load 
torque. The rest of this paper is organized as follows. Section 2 reviews the principle of the indirect fieldoriented control of induction motor. Section 3 shows the development of sliding mode controllers design for IM speed control. Section 4 gives the simulation and experimental results. Finally, some conclusions are drawn in section 5 .

\section{INDIRECT FIELD-ORIENTED INDUCTION MOTOR CONTROL}

A dynamic three-phase, Y-connected induction motor model is expressed in a $d$ - $q$ synchronously rotating frame as follows [1], [2], [3], [23], [24], [25], 26]:

$$
\begin{aligned}
& \frac{d i_{d s}}{d t}=\frac{1}{\sigma L_{s}}\left(V_{d s}-\left(R_{s}+\frac{L_{m}^{2}}{L_{r}^{2}} R_{r}\right) i_{d s}+\sigma L_{s} \omega_{e} i_{q s}+\frac{L_{m} R_{r}}{L_{r}^{2}} \phi_{d r}+\frac{L_{m}}{L_{r}} \phi_{q r} P \omega_{r}\right) \\
& \frac{d i_{q s}}{d t}=\frac{1}{\sigma L_{s}}\left(V_{q s}-\left(R_{s}+\frac{L_{m}^{2}}{L_{r}^{2}} R_{r}\right) i_{q s}-\sigma L_{s} \omega_{e} i_{d s}-\frac{L_{m}}{L_{r}} \phi_{d r} P \omega_{r}+\frac{L_{m} \cdot R_{r}}{L_{r}^{2}} \phi_{q r}\right) \\
& \frac{d \phi_{d r}}{d t}=\frac{L_{m} R_{r}}{L_{r}} i_{d s}-\frac{R_{r}}{L_{r}} \phi_{d r}+\left(\omega_{e}-P \omega_{r}\right) \phi_{q r} \\
& \frac{d \phi_{q r}}{d t}=\frac{L_{m} R_{r}}{L_{r}} i_{q s}-\left(\omega_{e}-P \omega_{r}\right) \phi_{d r}-\frac{R_{r}}{L_{r}} \phi_{q r} \\
& \frac{d \omega_{r}}{d t}=\frac{1}{J} T_{e}-\frac{f_{c}}{J} \omega_{r}-\frac{T_{l}}{J} \\
& T_{e}=\frac{3 \cdot P L_{m}}{2 \cdot L_{r}}\left(i_{q s} \cdot \phi_{d r}-i_{d s} \cdot \phi_{q r}\right)
\end{aligned}
$$

The main objective of induction motor vector control is, as in separately DC motors, to independently control torque and flux by using a $d-q$ reference frame rotating synchronously with the rotor flux space vector [2], [3], [26]. In ideally field-oriented control, the rotor flux vector is forced to align with $d$ axis and is set to be constant equal to the rated flux; it follows that [2], [4], [7], [21]:

$$
\begin{aligned}
& \phi_{q r}=\frac{d \phi_{q r}}{d t}=0 \\
& \phi_{d r}=\phi_{r}=\text { constant }
\end{aligned}
$$

Assuming that equations (7) and (8) are satisfied, i.e., field-oriented control is achieved, the torque equation becomes analogous to the separately DC motor and described as follows:

$T_{e}=\frac{3}{2} \frac{p \cdot L_{m}}{L_{r}} \cdot \phi_{r} \cdot i_{q s}$

Based on (4), slip frequency $\left(\omega_{s l}=\omega_{e}-\omega_{r}\right)$ is calculated using $i_{d s}^{*}$ and $i_{q s}^{*}$ as follows: $\omega_{s l}=\frac{1}{\tau_{r}} \frac{i_{q s}^{*}}{i_{d s}^{*}}$

Where superscript '*' represents referenced values.

Dynamic equations (1)-(5) then yield: 
$\frac{d i_{d s}}{d t}=-\left(\frac{R_{s}}{\sigma L_{s}}+\frac{1-\sigma}{\sigma \tau_{r}}\right) i_{d s}+\omega_{e} i_{q s}+\frac{L_{m}}{\sigma L_{s} L_{r} \tau_{r}} \phi_{d r}+\frac{1}{\sigma L_{s}} V_{d s}$

$\frac{d i_{q s}}{d t}=-\left(\frac{R_{s}}{\sigma L_{s}}+\frac{1-\sigma}{\sigma \tau_{r}}\right) i_{q s}-\omega_{e} i_{d s}-\frac{L_{m}}{\sigma L_{s} L_{r}} \phi_{d r} P \omega_{r}+\frac{1}{\sigma L_{s}} V_{d s}$

$\frac{d \phi_{r}}{d t}=\frac{L_{m}}{\tau_{r}} i_{d s}-\frac{1}{\tau_{r}} \phi_{d r}$

$\frac{d \omega_{r}}{d t}=\frac{3}{2} \frac{P L_{m}}{J L_{r}} i_{q s} \phi_{d r}-\frac{f_{c}}{J} \omega_{r}-\frac{1}{J} T_{l}$

Decoupling control with compensation chooses inverter output voltage so that $[2,4]$ :

$$
\begin{aligned}
& V_{d s}^{*}=\left(K_{p}+K_{i} \frac{1}{s}\right)\left(i_{d s}^{*}-i_{d s}\right)-\omega_{e} \sigma L_{s} i_{q s}^{*}-\frac{L_{m}}{L_{r} \tau_{r}} \phi_{d r} \\
& V_{q s}^{*}=\left(K_{p}+K_{i} \frac{1}{s}\right)\left(i_{q s}^{*}-i_{q s}\right)+\omega_{e} \sigma L_{s} i_{d s}^{*}+P \omega_{r} \frac{L_{m}}{L_{r}} \phi_{d r}
\end{aligned}
$$

Based on the above analysis, indirect field-oriented control (IRFOC) [1], [2], [3], [4] of induction motors with current-regulated PWM drives is reasonably represented as shown in Figure 1.

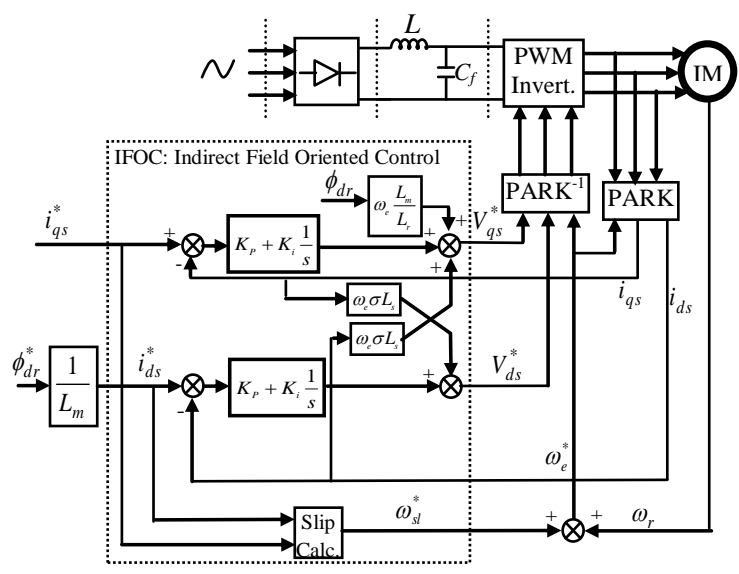

Figure 1. IRFOC scheme of the induction motor

\section{SPEED CONTROL OF IM USING SLIDING MODE CONTROL}

\subsection{Sliding mode control}

Variable structure control (VSC) with sliding mode, or sliding-mode control (SMC), is one of the effective nonlinear robust control approaches, because it provides system dynamics with an invariance property to uncertainties once the system dynamics are controlled in the sliding mode [11], [12], [15], [16], [17], [18], [19], 20]. The first step of SMC design is to select a sliding surface that models the desired closedloop performance in state variable space. Then the control is designed such

that the system state trajectories are forced toward the sliding surface and stay on it. The system state trajectory in the period of time before reaching the sliding surface is called the reaching phase. Once the system trajectory reaches the sliding surface, it stays on it and slides along it to the origin. The system trajectory sliding along the sliding surface to the origin is the sliding mode. The insensitivity of the controlled system to uncertainties exists in the sliding mode, but not during the reaching phase. Thus, the system dynamic in the reaching phase is still influenced by uncertainties [13], [14], [15], [16], [17]. 
Without lost of generality, consider the design of a sliding mode controller for the following second order system: $a_{1} \&+a_{2} x=b \cdot u$, where $u(t)$ is the input to the system and we assume that $b>0$. A possible choice of the structure of a sliding mode controller is [15-17]:

$u=u_{e q}+k \cdot \operatorname{sgn}(s)$

Where $u_{e q}$ is called equivalent control which dictates the motion of the state trajectory along the sliding surface [15], [16]; $k$ is a constant, representing the maximum controller output required to overcome parameter uncertainties and disturbances; $s$ is called the switching function because the control action switches its sign on the two sides of the switching surface $s=0$. For a second order system $s$ is defined as [16], [17]:

$s=\&+\lambda \cdot e$

Where $e=x_{d}-x$ and $x_{d}$ is the desired state; $\lambda$ is a constant and $\operatorname{sgn}(\mathrm{s})$ is the signum function, which is defined as:

$\operatorname{sgn}(s)=\left\{\begin{array}{cc}-1 & s<0 \\ 1 & s>0\end{array}\right.$

To make sure that the system trajectories move toward and stay on the sliding surface $s=0$ independent of the initial condition, the following sliding mode condition must be fulfilled [14], [15], 16]

$$
s \&-\eta \cdot|s| \Rightarrow s \&-\eta \cdot \operatorname{sgn}(s) s \Rightarrow \operatorname{sgn}(s) \leq-\eta
$$

Where $\eta$ is a positive constant, which ensures a finite time convergence to $\mathrm{s}=0$.

Using a sign function often causes chattering in practice. One solution is to introduce a boundary layer around the switching surface [14], [16], [20], [21]:

$$
u=u_{s}+u_{e q}
$$

Where:

$u_{s}=k \cdot \operatorname{sat}(s / \xi)$

Where the constant factor $\xi$ defines the thickness of the boundary layer and $\operatorname{sat}(\cdot)$ is a saturation function defined as:

$\operatorname{sat}(s / \xi)= \begin{cases}\operatorname{sgn}\left(\frac{s}{\xi}\right) & \left|\frac{s}{\xi}\right| \geq 1 \\ \frac{s}{\xi} & \left|\frac{s}{\xi}\right|<1\end{cases}$

The characteristic of $u_{s}$ versus $s$ is shown in Figure 2 . 


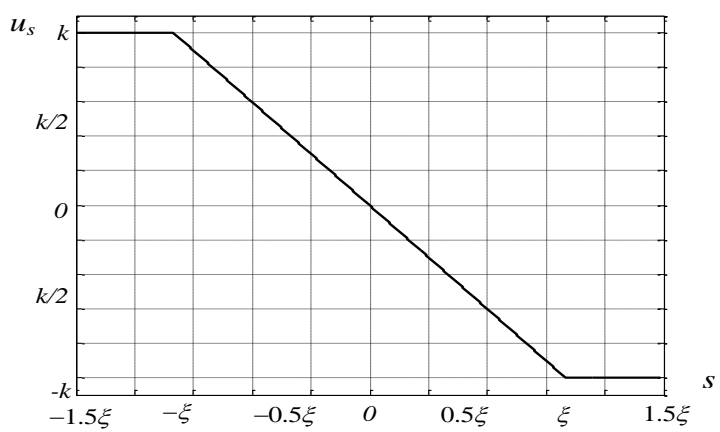

Figure 2. The discontinuous control action of the SMC control law $\left(u_{s}\right)$

\subsection{Speed and Current controllers design by sliding mode control}

In this section, we show the design procedure of the robust nonlinear control via the sliding mode control (SMC) for IM controlon order to obtain the IM control laws so as to achieve high-quality speed tracking performance. The design of the proposed sliding mode controller for an IM speed control involves the following steps.

\subsubsection{Design of sliding mode speed controller}

To control the speed of the induction motor, the sliding surface is defined as follows:

$s\left(\omega_{r}\right)=\omega_{r}^{*}-\omega_{r}$

Differentiating $s\left(\omega_{r}\right)$ with respect to time gives:

$\&\left(\omega_{r}\right)=\omega_{r}^{*}-\omega_{r}$

Taking into account the mechanical equation of the induction motor defined in the equation (14), the time derivative of sliding surface can be writing as follows:

$S\left(\omega_{r}\right)=\alpha_{r}^{*}-\left(\frac{3}{2} \frac{P^{2} L_{m} \phi_{d r}^{*}}{J L_{r}} . i_{q s}-\frac{f_{c}}{J} \oiint_{r}^{\&}-\frac{P}{J} T_{l}\right)$

We take

$i_{q s}=i_{q s}^{e q u}+i_{q s}^{n}$

During the sliding mode and at steady-state conditions, we have $s(\omega)=0, s(\omega)=0$ and $i_{q s}^{n}=0$, the equivalent control action can be defined as follows:

$i_{q s}^{e q u}=\frac{2}{3} \frac{J L_{r}}{P^{2} L_{m} \phi_{d r}^{*}}\left(\&_{r}^{*}+\frac{f_{c}}{J} \omega_{r}+\frac{P}{J} T_{l}\right)$

During the convergence mode, the condition $s\left(\omega_{r}\right) \cdot s\left(\omega_{r}\right)<0$ must be verified, thus guaranteeing motion of the state trajectory to the manifold. Substituting (28) into the time derivative of the sliding surface $\&\left(\omega_{r}\right)$ yields:

$\left\{\left(\omega_{r}\right)=-\frac{3}{2} \frac{P^{2} L_{m} \phi_{d r}^{*}}{J L_{r}} i_{q s}^{n}\right.$ 
The discontinuous control action can be given as:

$i_{q s}^{n}=k_{i q s} \cdot \operatorname{sat}\left(s(\omega) / \xi_{\omega}\right)$

To verify the system stability condition $\left(s\left(\omega_{r}\right) \cdot\left(\omega_{r}\right)<0\right)$, it is enough to choose a gain $k_{i q s}$ strictly positive. The stability proof of the sliding-mode speed controller is derived in the sense of the Lyapunov theorem and is shown in the appendix.

\subsubsection{Design of sliding mode current controllers}

The current loops are often the internal regulated loop in a field oriented controlled IM, and the global performance of the drive depends strongly on the performance of current control. Therefore, precise and fast current control is essential to achieve high static and dynamic performance for the FOC of IM. If the secondary currents are not adjusted precisely and with fast dynamics to the reference values, cross coupling will be caused between the motor torque and rotor flux. Thus, the performance of the FOC degrades [1], [2], [8], [14], [17].

The proposed control design uses two sliding mode controllers to regulate the $d$-axis and $q$-axis secondary currents respectively. The design of the controllers consists of two steps.

Firstly, we define sliding surfaces $s=\left[\begin{array}{ll}s_{1} & s_{2}\end{array}\right]=0$ as follows:

$$
\begin{aligned}
& s_{1}=i_{d s}^{*}-i_{d s} \\
& s_{2}=i_{q s}^{*}-i_{q s}
\end{aligned}
$$

Where $i_{d s}^{*}$ and $i_{q s}^{*}$ are the reference values of the $d$-axis and $q$-axis secondary currents, respectively. If the system stays stationary on the surface, then we obtain $s_{1}=s_{2}=0$. Substituting (31) and (32) into $s_{1}=0$ and $s_{2}=0$ yields

$i_{d s}=i_{d s}^{*}$
$i_{q s}=i_{q s}^{*}$

Secondly, we design a voltage control law that forces the system to move towards the sliding surface in a finite time.

Differentiating $s_{1}$ and $s_{2}$ with respect to time gives:

$$
\begin{aligned}
& \text { \& }=\text { d } \\
& \alpha=q_{q s}^{*}-i_{q s}^{k}
\end{aligned}
$$

Taking into account the equations of the induction motor defined in (11) and (12), the time derivative of sliding surface can be writing as follows:

$$
\begin{aligned}
\&= & i_{d s}-\frac{1}{\sigma L_{s}}\left(-\left(R_{s}+\left(\frac{L_{m}}{L_{r}}\right)^{2} R_{r}\right) \cdot i_{d s}+\sigma L_{s} \cdot \omega_{e} \cdot i_{q s}\right. \\
& \left.+\frac{L_{m} \cdot R_{r}}{L_{r}{ }^{2}} \cdot \phi_{d r}+V_{d s}\right) \\
\& & =i_{q s}^{\&}-\frac{1}{\sigma L_{s}}\left(-\sigma L_{s} \cdot \omega_{e} \cdot i_{d s}-\left(R_{s}+\left(\frac{L_{m}}{L_{r}}\right)^{2} \cdot R_{r}\right) \cdot i_{q s}\right. \\
- & \left.\frac{P \cdot L_{m}}{L_{r}} \phi_{d r} \cdot \omega_{r}+V_{q s}\right)
\end{aligned}
$$


We take

$v_{q s}=v_{q s}^{e q u}+v_{q s}^{n}$

$v_{d s}=v_{d s}^{e q u}+v_{d s}^{n}$

During the sliding mode and at steady-state conditions, we have $s_{1}=\&=0, s_{2}=\&=0$, $v_{d s}^{n}=0$ and $v_{q s}^{n}=0$, the equivalent control actions can be defined as follows:

$$
\begin{aligned}
& V_{d s}^{e q u}=\sigma \cdot L_{s}\left(d_{d s}^{\&}+\frac{1}{\sigma \cdot L_{s}}\left(R_{S}+R_{r} \cdot\left(\frac{L_{m}}{L_{r}}\right)^{2}\right) \cdot i_{d s}-\omega_{e} \cdot i_{q s}-\frac{L_{m} \cdot R_{r}}{\sigma \cdot L_{s} L_{r}^{2}} \phi_{r}^{*}\right)
\end{aligned}
$$

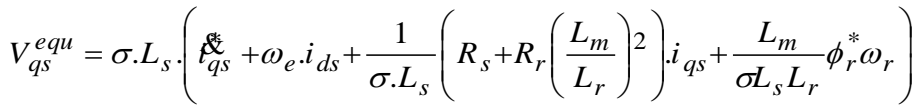

During the convergence mode, the condition $s_{1} \cdot \&<0$ and $s_{2} \cdot \&<0$ must be verified, thus guaranteeing motion of the state trajectory to the manifold. Substituting (38) and (39) into the time derivatives of the sliding surfaces $\&$ and yields:

$$
\begin{aligned}
& \&=-\frac{1}{\sigma L_{s}} v_{d s}^{n} \\
& \&=-\frac{1}{\sigma L_{s}} v_{q s}^{n}
\end{aligned}
$$

The discontinuous control actions can be given as:

$$
\begin{aligned}
& v_{d s}^{n}=k_{1} \cdot \operatorname{sat}\left(s_{1} / \xi_{1}\right) \\
& v_{q s}^{n}=k_{2} \cdot \operatorname{sat}\left(s_{2} / \xi_{2}\right)
\end{aligned}
$$

To verify the system stability condition $\left(s_{1} \cdot \&<0, s_{2} \cdot \&<0\right)$, it is enough to choose the gains $k_{1}$ and $k_{2}$ strictly positive and sufficiently larges.

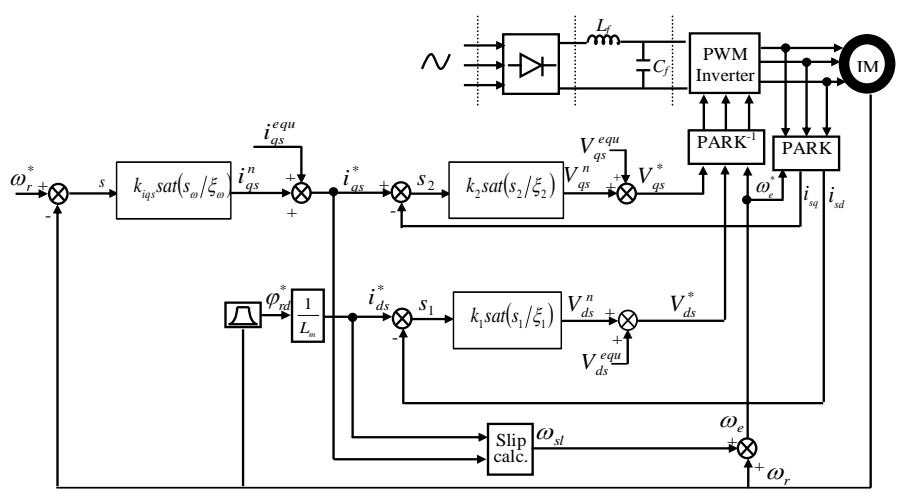

Figure 3. The block diagram of sliding mode speed and currents control of induction motor 


\section{SIMULATION AND EXPERIMENTAL RESULTS}

Based on the above analysis of IM drives control algorithm, Simulations were carried out in Matlab/Simulink to demonstrate the effectiveness of the proposed control scheme for IM speed control. Furthermore, an experimental test platform has been done in various operating conditions in order to verify the proposed method analysis. The motor parameters are given in Table I in the Appendix. The configuration of the adopted control scheme is drawn in Figure 3. It mainly consists of a induction motor (3 phases slipring), a ramp comparison voltage-controlled pulse width modulated (PWM) inverter, a slip velocity estimator, an inverse park transformation, indirect field oriented control bloc based on sliding mode currents controllers, and a speed feedback control loop contains a sliding mode controller. The experimental test setup exhibited shown in Figure 4 has been processed using a dSPACE DS1104 R\&D board with TMS320F240 DSP and ControlDesk experiment software. As shown in Fig. 4, it mainly consists of a 3-phase slip-ring induction motor, Y connected, four pole, $250 \mathrm{~W}, 1428 \mathrm{rpm} 220 / 380 \mathrm{~V}, 50 \mathrm{~Hz}$. and a $250 \mathrm{~W}$ DC motor serving for the load tests. An incremental encoder of $1024 \mathrm{p} / \mathrm{r}$ is used to measure the speed through the Inc-interface of dSPACE-1104. The parameters of the tested motor are the same with those used in the simulation.

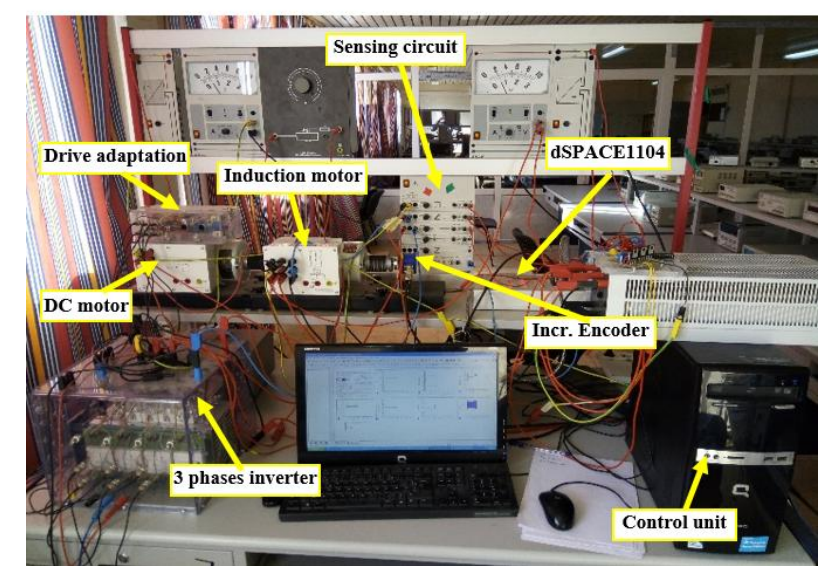

Figure. 4 Photographic view of the experimental drive system structure

\subsection{Simulation results}

Firstly, two different operating conditions for the induction motor are simulated to illustrate the operation of the proposed total sliding mode controller. We present the simulated results of the proposed total sliding mode control system for a rectangular shape-thrust command input and step reference for speed control. The parameter used in simulation are chosen as $k_{i q s}=25, k_{2}=k_{3}=40, \xi_{\omega r}=0.5, \xi_{1}=\xi_{2}=0.1$. These parameters are chosen to achieve the best transient performance in simulation considering the requirement of stability and possible operating conditions.

Test 1: The first test consists of constant speed reference. Where The machine is operated at $1000 \mathrm{rpm}$. Then, a nominal load torque disturbance $(0.75 \mathrm{~N} . \mathrm{m})$ is suddenly applied and eliminated at $15 \mathrm{sec}, 25 \mathrm{sec}$ respectively.

The performance of the proposed IM SMC speed control scheme is shown in Figures. 5(a)-(c). The speed is depicted in Figure. 5(a) and the direct and quadratic rotor fluxes $\phi_{d r}$ and $\phi_{q r}$ are depicted in Figure. 5(b). The phase current and the direct \& quadratic currents $I_{d s} \& I_{q s}$ are shown in Figure.5(c-e) respectively,.The Figure. 5 clearly shows that, the proposed total sliding mode control can achieve good tracking performance even in relation to load torque disturbance variation. In Figure. 5(a), the speed response of the proposed SMC is observed to present better tracking characteristics and more robustness (minimal rising time with no overshoot and very rapid rejection of the load disturbance, with a small undershoot). It should be noted that, with the proposed scheme, the $d$-axis rotor flux level is kept constant at its nominal value which highlights a proper cross coupling and an accurate field orientation $\left(\phi_{q r}=0\right)$ Figure. 5(b). 


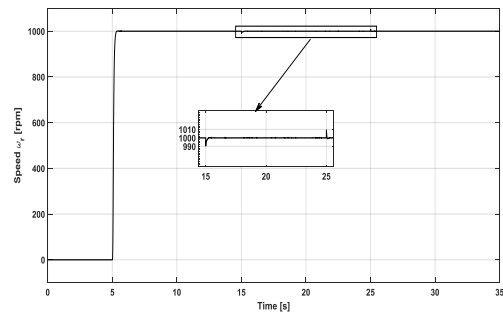

(a)

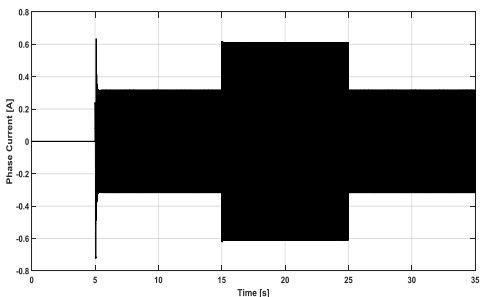

(c)

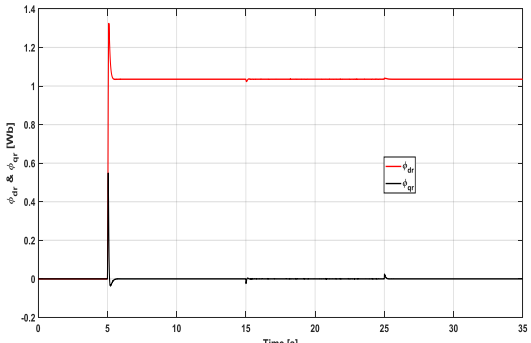

(b)

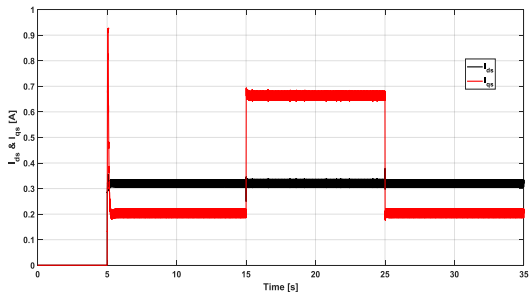

(d)

Figure 5. Simulated results of SMC IM drive during the $1^{\text {st }}$ test operation (a) Speed, (b) $d$ - \& $q$-axis rotor fluxes, (c) phase current, (d) d- \& q-axis stator currents

Test 2: the effectiveness of the proposed IM Total SMC has been tested under regenerating operation mode. This second test consists of step change on speed reference from 1000rpm to -1000rpm where reference speed is brutally reversed at $35 \mathrm{sec}$. Then, a load torque of $0.75 \mathrm{~N} . \mathrm{m}$ has been applied and eliminated at $\mathrm{t}=15 \mathrm{sec}$ and $\mathrm{t}=25 \mathrm{sec}$. respectively.

The performance of IM Total SMC under this operating points test is depicted in Figure. 6(a-e).The speed is depicted in Figure. 6(a). The direct and quadratic secondary fluxes are depicted in Figure. 6(b). The phase current and the direct \& quadratic currents $I_{d s} \& I_{q s}$ are shown in Figure. 6(c,d) respectively. The obtained results shown in Figure.6 prove that the Total SMC IM drives has good control performance in fluxes responses and keeps the same characteristics against speed reference reversals. Also, they demonstrate that the proposed Total SMC has a powerful capability to reject the load torque disturbances. It is clearly observed that the proposed scheme gave satisfactory performances thus judges that the controller is robust.

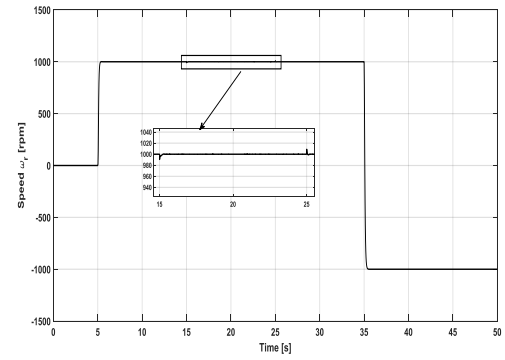

(a)

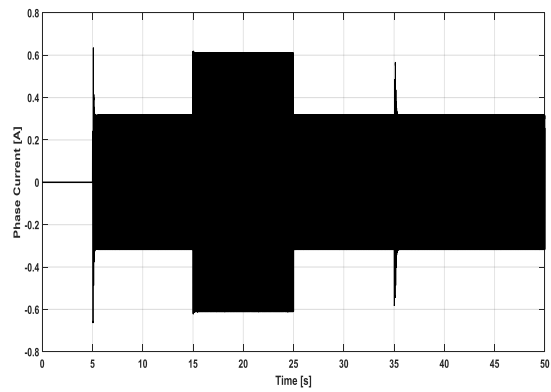

(c)

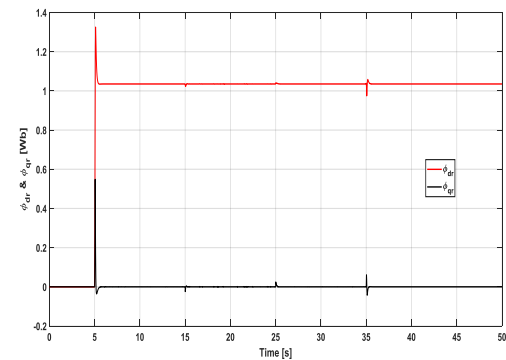

(b)

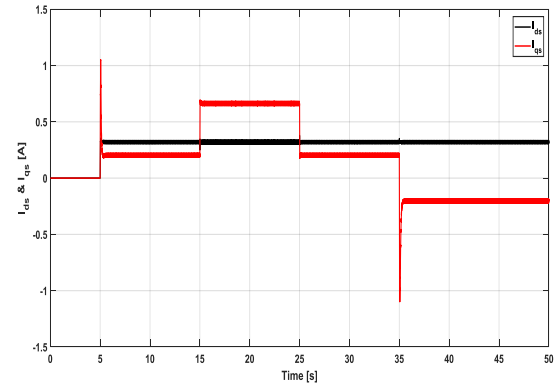

(d)

Figure. 6. Simulated results of SMC IM drive during the $2^{\text {nd }}$ test operation (a) Speed, (b) $d$ - \& $q$-axis rotor fluxes, (c) phase current, (d) d- \& q-axis stator currents 


\subsection{Experimental results}

In order to make a comparison study between numerical simulation and experimental validation results of the proposed total SMC induction motor drive, the same scenario tests seen in section 4.1 have been done in this section. Figures 7(a-e) shows the performance of the SMC induction motor drives scheme for the test 1 . The results presented in Figure. 7(a) shows the rotor speed and the rotor fluxes $\left(\phi_{d r}\right.$ and $\left.\phi_{q r}\right)$ are plotted in figure. 7(b). The phase current and the direct \& quadratic currents $I_{d s} \& I_{q s}$ are shown in Figures. 7(c,d) respectively. These figures show that the proposed control scheme presents good tracking characteristics and more effectiveness against speed and load torque application. It is observed from the obtained results that this controller rejects the load disturbance very rapidly with no overshoot and with a negligible steady state error, and the $d$-axis rotor flux is maintained at its nominal value.

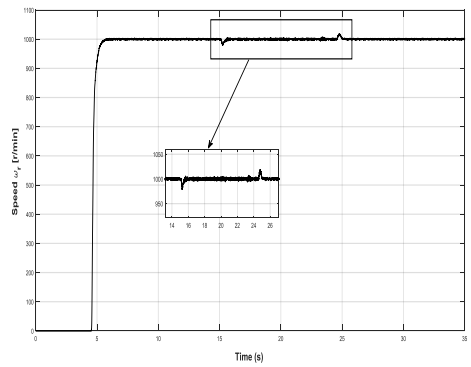

(a)

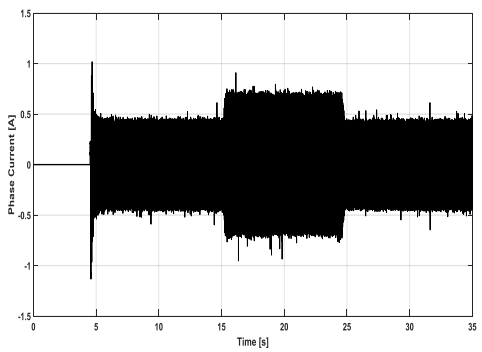

(c)

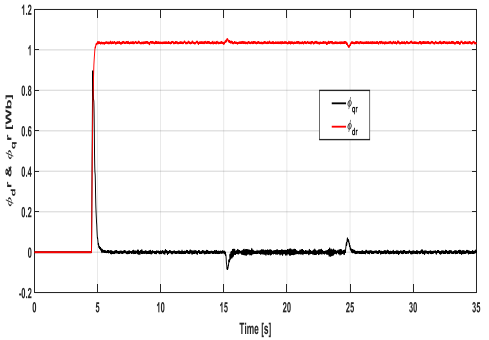

(b)

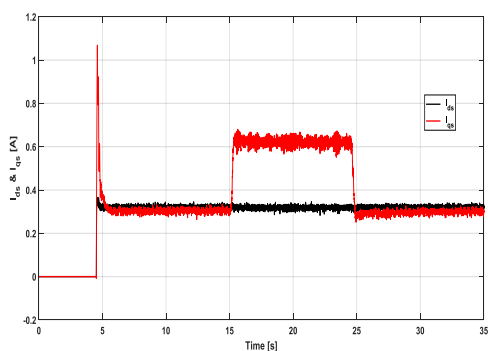

(d)

Figure. 7. Experimental results of SMC IM drive during the 1 st test operation (a) Speed, (b) d- \& q-axis rotor fluxes, (c) phase current, (d) d- \& q-axis stator currents

For the second test, the performance of the proposed control scheme with SMC is shown in figures $8(\mathrm{a}-\mathrm{e})$. The rotor speed and the rotor fluxes $\left(\phi_{d r}\right.$ and $\left.\phi_{q r}\right)$ are displayed in figures 8(a) and 8(b), respectively. The phase current and $I_{d s} \& I_{q s}$ currents are shown in Figure. 8(c,d) respectively. The obtained results presented in Figure. 8 which are identical to simulation, show that the rotor speed follows the reference with negligible steady-state error, minimal overshoot and a small rise time. In addition, the $d$-component of the rotor flux is maintained to its nominal value which proves a good cross coupling, accuracy, and robustness of the proposed Sliding mode controller.

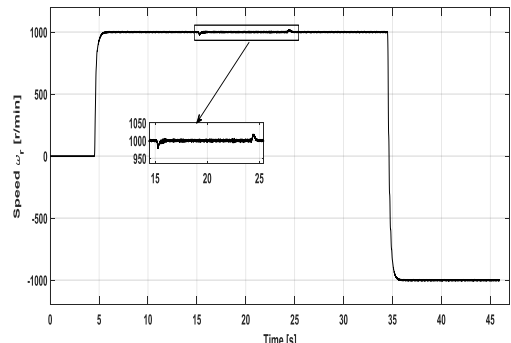

(a)

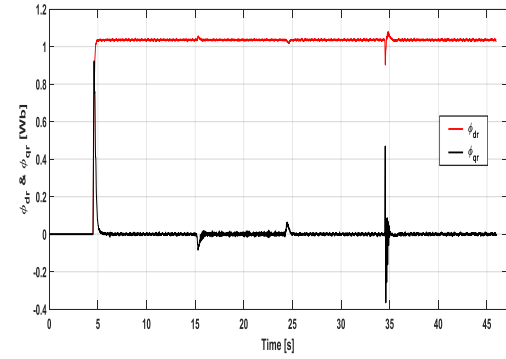

(b)

Figure. 8. Experimental results of SMC IM drive during the 2 nd test operation (a) Speed, (b) d- \& q-axis rotor fluxes, (c) phase current, (d) d- \& q-axis stator currents 


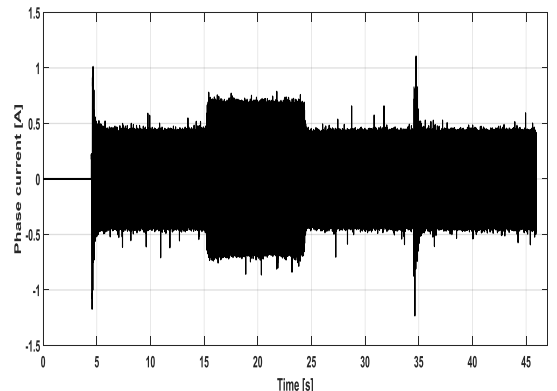

(c)

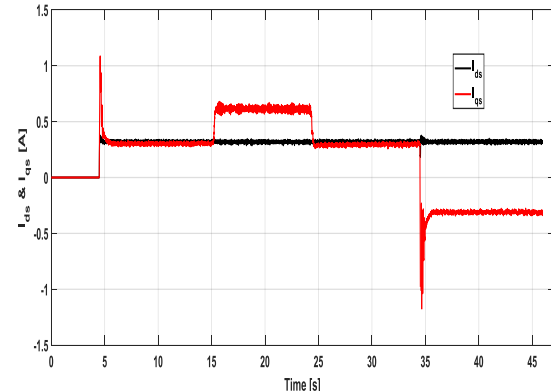

(d)

Figure. 8. Experimental results of SMC IM drive during the 2nd test operation (a) Speed, (b) d- \& q-axis rotor fluxes, (c) phase current, (d) d- \& q-axis stator currents

\section{CONCLUSION}

This paper has experimentally demonstrated the application of a nonlinear total sliding mode control system for the speed control of an IM drive. Firstly; an indirect field-oriented control of IM was designed. Moreover, a sliding mode control design technique is investigated to achieve a torque, flux and speed tracking objective under disturbance of the load torque. The effectiveness of the proposed control dynamics has been successfully verified by numerical simulation and experimentation.

The obtained simulation and experimental results show clearly that the proposed sliding mode controller has presented satisfactory performances which provide good control performances with high accuracy and convergence against load torque disturbances and speed reference changes. Moreover, it provides desirable decoupling between flux and torque.

Table 1. Terms and Abbreviations

\begin{tabular}{lc}
\hline \multicolumn{1}{c}{ Symbols } & Designation \\
\hline$i_{d s}, i_{q s}$ & Direct and quadrature stator currents. \\
$V_{d s}, V_{q s}$ & Direct and quadrature stator voltages \\
$J$ & Inertia moment \\
$k_{p}, k_{i}$ & controller \\
$L_{s}, L_{r}, L_{m}$ & Stator and rotor and mutual inductances \\
$P$ & Number of pole pairs \\
$R_{s}, R_{r}$ & Stator and rotor resistances \\
$\phi_{d r}, \phi_{q r}$ & Direct and quadrature rotor fluxes. \\
$\tau_{r}$ & \\
$\omega_{e}$ & Rotor time constant ( $\left.L_{r} / R_{r}\right)$ \\
$\omega_{r}$ & Synchronous frequency \\
$\omega_{s l}$ & Mechanical rotor frequency \\
$T_{e m}, T_{L}$ & Slip frequency \\
$\sigma=1-L_{m}^{2} / L_{s} L_{r}$ & Electromagnetic and load torques \\
IM & Leakage coefficient \\
DC & Induction motor \\
IRFOC & Direct current \\
SMC & Indirect rotor field-oriented control \\
\hline
\end{tabular}


Table 2. Induction Motor Parameters

\begin{tabular}{ccc}
\hline Designation & Symbol & Quantity \\
\hline Rated Power & $P_{n}$ & $250 \mathrm{~W}$ \\
Line-to-Line voltage & $V_{n}$ & $398 \mathrm{~V}$ \\
Rated current & $I_{n}$ & $0.86 \mathrm{~A}$ \\
Rated speed & $\omega_{r n}$ & $1360 \mathrm{rpm}$ \\
Number of pole pairs & $P$ & 2 \\
Stator resistance & $R_{s}$ & $39.26 \Omega$ \\
Rotor resistance & $R_{r}$ & $35.6015 \Omega$ \\
Stator inductance & $L_{s}$ & $3.6076 \mathrm{H}$ \\
Rotor inductance & $L_{r}$ & $3.6076 \mathrm{H}$ \\
Magnetizing inductance & $L_{m}$ & $3.233 \mathrm{H}$ \\
Inertia moment of motor & $J$ & $0.0013 \mathrm{~kg} / \mathrm{m}^{2}$ \\
Friction coefficient & $f_{c}$ & $0.0037 \mathrm{Nm} . \mathrm{s} / \mathrm{rad}$ \\
\hline
\end{tabular}

\section{REFERENCES}

[1] J. P. Caron and J. P. Hautier (1995), "Modelling and Control of Induction Machine", Technip Edition, France..

[2] L. Baghli, "Contribution to Induction Machine Control: Using Fuzzy Logic, Neural Networks and Genetic Algorithms", Doctoral Thesis, Henri Poincare University, January 1999 (text in french).

[3] N. P. Quang and J.-A. Dittrich, Vector Control of Three-Phase AC Machines: System Development in the Practice, Springer- Verlag Edition, 2015

[4] R. -J. Wai, "Adaptive Sliding-Mode Control for Induction Servomotor Drives", IEE Proc. Elecrr. Power Appl., 2000,147, pp. 553-562.

[5] C. -M. Lin and C. -F. Hsu, “Adaptive Fuzzy Sliding-Mode Control for Induction Servomotor Systems”, IEEE Transactions on Energy Conversion, vol. 19, n², June 2004, pp. 362-368

[6] R. -J. Wai, C. -M. Lin and C. -F. Hsu, "Adaptive Fuzzy Sliding-Mode Control for Electrical Servo Drives", Fuzzy Sets and Systems 143 (2004) 295-310.

[7] J. C. Le and Y. -H. Kuo, "Decoupled fuzzy sliding-mode control", IEEE Trans. on Fuzzy Systems, Vol. $6 N^{\circ} 3$, 1998.

[8] S. Krim, S. Gdaim, A. Mtibaa, M. F. Mimouni, "FPGA-Based Implementation Direct Torque Control of Induction Motor", International Journal of Power Electronics and Drive Systems IJPEDS, VOL 5, Nº3, 2015

[9] O. Boughazi, A. Boumedienne, H. Glaoui, "Sliding Mode Backstepping Control of Induction Motor", International Journal of Power Electronics and Drive Systems IJPEDS, VOL 4,N4, 2014

[10] B. K. Bose, "Modern Power Electronics and AC Drives", Printice Hall PTR, USA, 2002, ISBN 0-13-016743-6.

[11] A. Gouichiche, M. S. Boucherit, A. Safa, Y. Messlem, "Sensorless Sliding Mode Vector Control of Induction Motor Drives", International Journal of Power Electronics and Drive Systems IJPEDS, VOL 2,º3, 2012

[12] H. Echeikh, R Trabelsi, A. Iqbal, M.F Mimouni, R Alammari, "Online Adaptation of Rotor Resistance based on Sliding Mode Observer with Backstepping Control of A Five-Phase Induction Motor Drives”, International Journal of Power Electronics and Drive Systems IJPEDS, VOL 7,N³, 2016

[13] M. Jannati, A. Monadi, N. Rumzi N. Idris, M. J. Abdul Aziz, "Speed Sensorless Vector Control of Unbalanced Three-Phase Induction Motor with Adaptive Sliding Mode Control”, International Journal of Power Electronics and Drive Systems IJPEDS, VOL 4,N³, 2014

[14] V. I. Utkin, "Sliding Mode Control Design Principles and Applications to Electric Drives", IEEE Trans. Ind. Electr., Vol. 40. No 01, 1993, pp. 23-36.

[15] J. J., Slotine, “Applied Nonlinear Control”, Prentice-Hall. Inc., 1991, ISBN 0-13-040890-5.

[16] R. -J. Wai, "Adaptive Sliding-Mode Control for Induction Servomotor Drives", IEE Proc. Elect. Power Appl., 2000, Vol. 147, pp. 553-562.

[17] S. M. Nayeem Hasan; Iqbal Husain, A Luen-berger-Sliding Mode Observer for Online Parameter Esti-mation and Adaptation in High-Performance Induction Motor Drives, IEEE Transactions on Industry Applications, Vol. 45, Issue: 2,2009 , pp. $772-781$.

[18] C. -M. Lin and C. -F. Hsu, “Adaptive Fuzzy Sliding-Mode Control for Induction Servomotor Systems”, IEEE Transactions on Energy Conversion, vol. 19, n², June 2004, pp. 362-368

[19] R. -J. Wai, C. -M. Lin and C. -F. Hsu, "Adaptive Fuzzy Sliding-Mode Control for Electrical Servo Drives", Fuzzy Sets and Systems 143, 2004, 295-310.

[20] S. G., Tzafestas and G. G., Rigatos, "Design and Stability Analysis of a New Sliding-Mode Fuzzy Logic Controller of Reduced Complexity", Machine Intelligence \& Robotic Control, Vol. 1, No. 1, 1999, pp. 27-41.

[21] A. M. Trzynadlowski, "Control of Induction motors", Academic Press USA, 2001.

[22] P. Vas, "Sensorless vector and Direct Torque control", Oxford University Press, 1998. 
[23] S. Rafa, A. Larabi, L. Barazane, M. Manceur, N. Essounbouli, A. Hamzaoui, "Implementation of a new fuzzy vector control of induction motor", ISA Transactions, Volume 53, Issue 3, May 2014, Pages 744-754

[24] LI Zhen, Longya Xu, “On-Line Fuzzy Tuning of Indirect Field-Oriented Induction Machine Drives”, IEEE Trans. on Power Electronics, Vol. 13 n¹ (1998).

[25] A. Hazzab, I. K. Bousserhane, M. Zerbo, P. Sicard, "Real Time Implementation of Fuzzy Gain Scheduling of PI Controller for Induction Motor Machine Control", Neural Processing Letters (2006) 24:203-215.

[26] F.-J. Lin, R.-J. Wai, H.-J. Shieh, "Robust control of induction motor drive with rotor time-constant adaptation", Electric Power Systems Research 47 (1998) 1-9.

\section{BIOGRAPHIES OF AUTHORS}
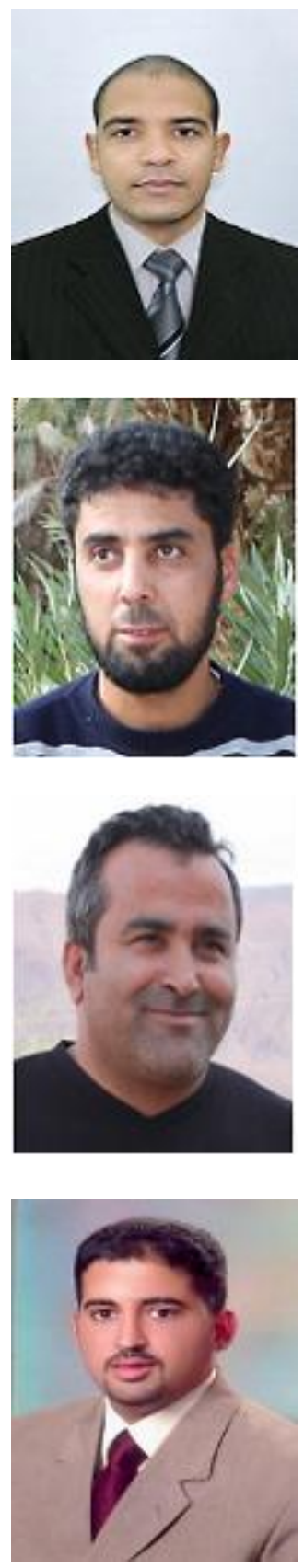

Aymen Omari was born in Bechar, Algeria, in 1987. He received the L.Sc. and M.Sc. degrees in electrical and electronics engineering from Bechar University, Bechar, Algeria, in 2010 and 2012, respectively. Where he has been working toward the Doctoral degree in the Department of Electrical and Electronics Engineering since September 2013. He is currently a Research member Laboratory Control, Analysis and Optimization of Electro-energy Systems, Department of Electrical and Electronics Engineering, Bechar University. His main research activity is focused on electrical motor drives, power electronics, process control.observer and estimator design for induction motor drive systems.

Bousserhane Ismail Khalil received his BS degree in Electrical Engineering from the Electrical Engineering Institute of the University Center of Bechar in 2000. He then received his MS and PhD degrees in Electrical Engineering from the University of Sciences and Technology of Oran (Algeria) in 2003 and 2008, respectively. He is currently a Professor of Electrical Engineering at the University of Bechar, Bechar, Algeria. His areas of interest include modern control techniques and their application in electric drives control.

Hazzab Abdeldjebar received his State Engineer, MS, and $\mathrm{PhD}$ degrees in Electrical Engineering from the Electrical Engineering Institute of The University of Sciences and Technology of Oran (USTO), Algeria in 1995, 1999, and 2006, respectively. He is currently a Professor of Electrical Engineering at the University of Bechar, Bechar (Algeria), where he has been the Director of the Research Laboratory of the Command, Analyses, and Optimization of Electro-Energetic Systems since 2009. His research interests include power quality, modeling, modern controller and observer design for nonlinear systems, control of power electronics, multidrive systems and electrical vehicle, and adaptive control and nolinear systems diagnostic.

BouchibaBousmaha was born in 1977 at Bechar-Algeria, he's received the electrical engineering diploma from Bechar University, Algeria in 1999, and the Master degree from the University Alexandria Egypt in 2006 and the Ph.D. degree from the Electrical Engineering Institute of the SDB in 2011. Currently, he is an assistant professor at Bechar University. Where he is member of the Research Laboratory of Control Analysis and Optimization of the Electro-Energetic Systems. His research interests include power electronics, electric drives control, and artificial intelligence and their applications. 